Document downloaded from:

http://hdl.handle.net/10251/166836

This paper must be cited as:

Noverques-Medina, A.; Juste Vidal, BJ.; Sancho, M.; García-Fayos, B.; Verdú Martín, GJ. (2020). Study of the influence of radon in water on radon levels in air in a closed location. Radiation Physics and Chemistry. 171:1-7.

https://doi.org/10.1016/j.radphyschem.2020.108761

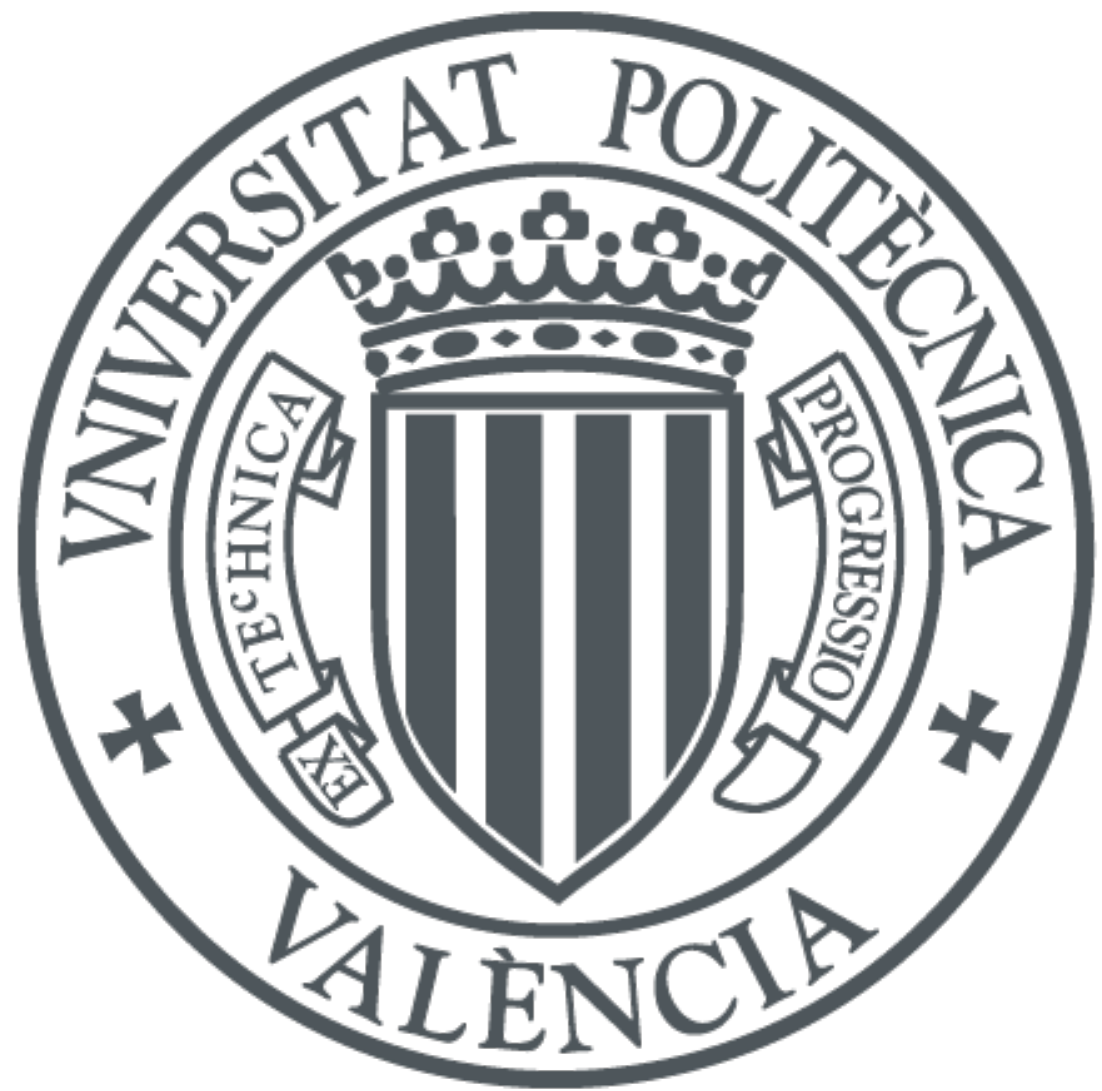

The final publication is available at

https://doi.org/10.1016/j.radphyschem.2020.108761

Copyright Elsevier

Additional Information 


\title{
Study of the influence of radon in water on radon levels in air in a closed location
}

A. Noverques, B. Juste, M. Sancho, B. García-Fayos, G. Verdú

Institute for Industrial, Radiophysical and Environmental Safety (ISIRYM), Universitat Politècnica de València, Camino de Vera s/n 46022 Valencia (Spain)

Tel.: +34 963876334; Fax: +34 963877639; e-mail: ainome@iqn.upv.es

\begin{abstract}
Radon, radioactive gas that comes from uranium and radium decay was considered as a carcinogenic element by the World Health Organization in 2010. The hazard of this gas resides in two of its descendants, the ${ }^{214} \mathrm{Po}$ and ${ }^{218} \mathrm{Po}$, solid particles that adhere to the aerosols present in the air and are deposited in human lungs causing damage to its tissue. In closed spaces, radon tends to accumulate in the air reaching levels above the legislative limits established in the Directive 59/2019/EURATOM. However, radon is present not only in the air but also in soil, water and building materials. In this research it has been investigated water as a radon source. Due to its high variability, the main objective of this research is to study the influence of water radon concentration into air radon concentration in two situations: at a laboratory scale and in a real installation. For this purpose, an experimental device was designed at laboratory scale to analyze this influence in stable conditions of temperature, relative humidity and atmospheric pressure, thus reducing the interference of these variables in radon measurements. For field measurements, the radon levels in water and its possible influence on the increase in air concentration in a Waste Water Pre-Treatment Plant (WWPTP) have been analyzed.
\end{abstract}

Keywords: radon in water, radon influence in air, RadonScout Plus, Corentium Pro, Hidex 600 SL

\section{Introduction}

Radon is a gas that comes from the radioactive decay of uranium and radium with short half-life (3.8 days). It is very soluble in organic compounds, with a value of 12.7 for solubility in toluene scintillation at $20^{\circ} \mathrm{C}$ (Pritchard et Gessell, 1977) or 6.25 in olive oil at $37^{\mathrm{a}} \mathrm{C}$ (Nussbaum et Harsh, 1958). The Ostwald solubility coefficient has been also estimated in fatty acids and triglycerides concluding that it increases in a regular fashion with the number of carbon atoms per molecule: 1.05 for formic acid, 4.43 for acetic or 7.55 trioctanoin, at $25^{\circ} \mathrm{C}$ (Nussbaum et Harsh, 1958). However, solubility is reduced with a temperature increase: 0.96 formic acid, 3.53 acetic and 6.12 trioctanoin at $37^{\circ} \mathrm{C}$ (Nussbaum et Harsh, 1958). This solubility decreases in water varying slightly according different researches: 0.255 at $20^{\circ} \mathrm{C}$ (Pritchard et Gessell, 1977) and 0.196 at $18^{\circ} \mathrm{C}$ water salinity or 0.293 for freshwater (Schubert et al, 2012).

Due to its gaseous nature, radon emanates to the surface and gets inside buildings both by convection and diffusion processes. Its descendants, ${ }^{218} \mathrm{Po}$ and ${ }^{214} \mathrm{Po}$, which emit alpha particles, could be inhaled and deposited in the human lungs where they cause cellular damage. In 1988, the World Health Organization (WHO) classified radon as a human carcinogenic (WHO, 2009). It is considered the first cause of lung cancer in non-smokers, and the second cause in smokers. It is estimated that between 3-14\% of the lung cancer human deaths are caused by radon (Matos, 1997).

Due to the great social and health relevance with reference to radon (from here, ${ }^{222} \mathrm{Rn}$ ), in 2013 the Official Journal of the European Union published Directive 2013/59/EURATOM that establishes limit values of air radon concentration in buildings, workplaces and dwellings $\left(300 \mathrm{~Bq} \cdot \mathrm{m}^{-3}\right)$, and defines action plans against radon exposure in air in the mentioned locations. This legislation emphasizes the control of air radon concentrations in dwellings.

Although radon occurs naturally, there are different sources in which it can be found: soil, in greater or lesser amounts depending on the type of the rock; water, when gas is dissolved in it, or in building materials, if raw materials contained high concentrations of uranium or radium. In Spain, there is a predictive radon concentration map in air which is based on the geographical probability of finding radon in soils (CSN, 2017). However, there are fewer references regarding the water radon concentrations. Some of these researches refers to radon levels in groundwater discharges (Moreno et al., 2014; Baudron et al., 2015) or radon levels in spas (Soto et al., 1995; Ródenas et al., 2008).

According to Directive 2013/51/EURATOM it is established that countries must set a threshold level that can range between $100 \mathrm{~Bq} \cdot \mathrm{L}^{-1}$ and $1000 \mathrm{~Bq} \cdot \mathrm{L}^{-1}$ for the amount of radon in water for human consumption. In Spain, at current legislation (Real Decreto 314/2016) a range between $100 \mathrm{~Bq} \cdot \mathrm{L}^{-1}$ and $500 \mathrm{~Bq} \cdot \mathrm{L}^{-1}$ is set for the concentration of radon in drinking water. However, radon exposure from aquatic sources show two different pathways: ingestion of water and inhalation of the radon released by water. It is considered that the risk of suffering cancer derived from inhalation of radon contained in water (while doing domestic chores or having a shower) is greater than the intake of water with a certain radon content (Zeeb et al, 2015). It isimportant to analyze radon transfer phenomena from water to air; not only during domestic consumption in dwellings, but also in industries such as ceramics or water treatment plants, where high amounts of water are used. In case of the water containing radon, this gas will be transferred to the air being a risk for workers. This is why, in this research, it is studied the influence of radon in water on radon levels in air, both at laboratory scale, and at real scale. For laboratory scale tests, it has been designed an experimental device that allows to study this influence in stable and reproducible conditions due to the slight variation of external conditions such as temperature, relative humidity and atmospheric pressure. Likewise, a real case of radon in water influence has been studied in a Waste Water Pre-Treatment Plant. 


\section{Methods and materials}

\subsection{Materials for radon measurements}

This section details all the detectors selected for radon measurements according to practicality, experience (Noverques, 2017) and economic criteria. Additionally, the available detectors at the research institute, as well as their calibrations and some of their participation on intercomparisons has been taken into account (Noverques, 2018). Also, among the different types of available detectors for radon in air, those that carry out continuously measurements have been selected. Although they require a power supply, they enable measurements of the integration of the radon accumulated period

To analyze the concentration of radon in water RAD7-H2O, E-PERM System for Radon in Water and Liquid Scintillator Hidex 600SL were used. For radon measurements in air, RadonScout Plus, CorentiumPro and E-PERM System were selected.

\subsubsection{Radon measurements in water}

RAD7-H2O (Durridge Company) was used to measure radon concentration in $40 \mathrm{~mL}$ vials of water samples. RAD7 is a continuous monitor that uses an alpha solid state decay detector. It consists of a semiconductor material (silicon) with implanted ions which transforms the received alpha radiation into an electrical signal. A high voltage supply circuit charges the internal conductor and creates an electric field in the entire cell which drives the particles that are positively charged to place them on the detector. The energy of alpha particles makes up the spectrum of characteristic energy for each sample taken. Monitor RAD7 pumps water sample and removes radon from water transferring into the air where it is placed for transportation into a drying tube when humidity is removed.

. It offers the radon concentration results in $\mathrm{Bq} \cdot \mathrm{L}^{-1}$ directly in each measurement. The accuracy of the RAD7 is estimated to be better than $5 \%$ based on manufacturer information (Manual RAD7, 2000).

The E-PERM System (Rad Elec Inc.) consists on an electret connected to a chamber where the radon gas diffuses. The electret is a Teflon disc with positive charge, housed in an electrically conductive plastic support. As radon and its descendants decay within a chamber containing the electret, the release of alpha and beta particles occurs. These particles collide with the air molecules causing the ionization. The resulting air molecule in this shock remains with positive or negative charge. The negatively charged ions are attracted to the surface of the electret, charged positively, and voltage reduction occurs. The precision of the detector is lower than $10 \%$ depending of the range concentration. For radon measurements in water, the sample is taken by a $67 \mathrm{~mL}$ vial, and then they are exposed to a suspended E-PERM placed inside a large sealed measurement jar during three days approximately. The detector, previously opened and measured the initial voltage, is suspended on the water sample that contains radon. The difference between the initial and the final electret voltage, during a known period of time, allows to determine radon concentration in water sample in $\mathrm{Bq} \cdot \mathrm{L}^{-1}$ (Kotrappa, E-PERM System Manual, 1996; User Manual E-PERM. Radon in water, 2008).

The liquid scintillation counter (LSC) Hidex 600SL (Hidex Company) also used for radon water measurements is a triple to double coincidence detector that allows the detection of ionizing radiation. Its principle is based on the property that some substances could emit light when they are crossed by radiation. In this case, the method used is the extraction: there is a water sample of $8 \mathrm{~mL}$ mixed with $12 \mathrm{~mL}$ of cocktail. Radon-222 is extracted from water to water-immiscible cocktail (Hidex 600 SL Manual, 2017). The accuracy of this detector is set at $10 \%$ according to manufacturer.

\subsubsection{Radon measurements in air}

RadonScout Plus (SARAD Company) is a continuous monitor, with a high voltage silicon semiconductor detector. The air radon concentration is measured through the short-lived radon descendants $\left({ }^{218} \mathrm{Po}\right)$ that comes from the Rn decay inside the chamber. After it, the ${ }^{218}$ Po remains positively charged for a short period of time due to shell electrons are scattered away by the emitted alpha particle. These positive ions are captured by the electric field on the surface of the semiconductor detector. The number of ${ }^{218} \mathrm{Po}$ ions collected is proportional to the amount of ${ }^{222} \mathrm{Rn}$ inside the chamber. The balance between $\mathrm{Rn}$ and ${ }^{218} \mathrm{Po}$ is reached in approximately 15 minutes. The precision of this detector is set at $5 \%$ (RadonScout Plus User Manual, 2017)

CorentiumPro (AirThings AS) samples the internal air in a passive diffusion compartment and, using alpha spectrometry, calculates radon levels accurately. Due to its silicon photodiodes, it detects radon to count and measure the energy of alpha particles resulting from the radon decay chain. The detector precision is set at $5 \%$ after 24 hours measuring (User Manual CorentiumPro, 2008).

In addition, the air radon detection system based on electrets has also been used. In this case, the electret is screwed into a chamber and exposed inside a box through which radon-containing air circulates. Radon measurements in air are always done in duplicate. 


\subsection{Study of the influence of water radon concentration transference into air radon concentration at} laboratory scale

\subsubsection{Design of the experimental device}

The main objective of this design is to develop an experimental device that allows simultaneous measuring of air and water radon concentrations in steady atmospheric conditions. In this way, the possible relationship between both concentrations could be analyzed. The device consists of a tank of high density polyethylene of $120 \mathrm{~L}$, impermeable to radon, hermetically sealed on the surface thereof. At the bottom of the tank a pitchblende stone is introduced (see Fig. 1), with an activity of $45.09 \mathrm{kBq} \cdot \mathrm{kg}^{-1}$, which will be the source of radon for all the tests carried out. Additionally, a metallic support is placed inside the tank above the pitchblende stone where the RadonScout will be located for radon in air measurements (see Fig. 1). There is installed a water tap at $25 \mathrm{~cm}$ from the bottom, which will be used to sample water whose top level must be above the tap as shown in Fig. 1.

This experimental equipment shown at Fig 1. has been used for the study at laboratory scale, for two different purposes: source characterization, which allows knowing some parameters such as radon emission rate, and the study of the influence of radon in water on the levels of radon in air.

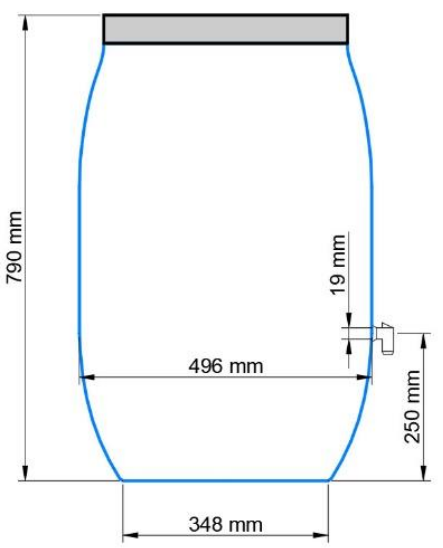

(A)

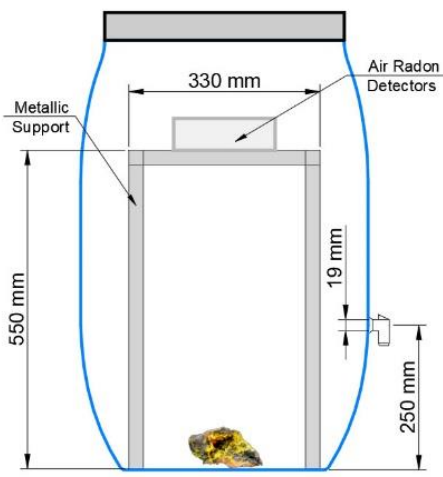

(B)

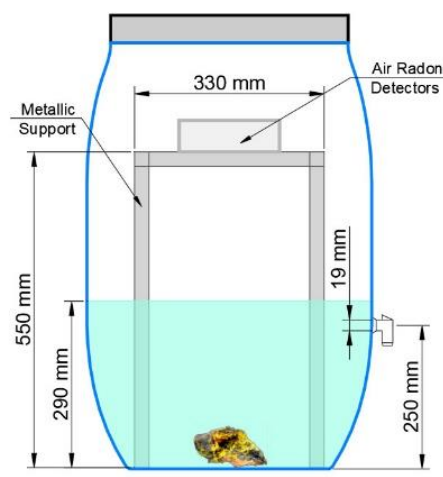

(C)

Fig. 1. Diagram of the experimental device: (A) dimensions of the tank; (B) arrangement of elements for source characterization; (C) arrangement of elements for water to air transference tests

\subsubsection{Theoretical model for radon concentration evolution}

This section details the mathematical model (Closed Compartment Model, CCM) that is applied to characterize the radon source and predict the concentration in air after a certain exposure time. The CCM is used to analyze the evolution of radon concentration inside the tank when there is just air, in a system isolated from the environment and with no external water supply (Kowalczk, 2010; Sainz et al., 2016), as the one used in this work. The differential equation that determines this situation is given by Eq. (1):

$$
\frac{d C_{R n}}{d t}=\phi-\lambda C_{R n}
$$

Where $C_{R n}$ is air radon concentration $\left(\mathrm{Bq} \cdot \mathrm{m}^{-3}\right), \phi$ is the radon emission rate in $\mathrm{Bq} \cdot \mathrm{m}^{-3} \cdot \mathrm{h}^{-1}$, and $\lambda$ is a decay constant $\left(\mathrm{h}^{-1}\right)$ which includes the two contributions shown in equation (2): $\lambda_{R n}$, which is the radon decay constant $\left(\mathrm{h}^{-1}\right)$ and $\lambda_{v}$, which is the system leakage constant.

$$
\lambda=\lambda_{R n}+\lambda_{v}
$$

Applying the constant variation method, the equation for the evolution of radon concentration results in the following expression:

$$
C_{R n}(t)=C_{0} e^{(-\lambda t)}+\frac{\phi}{\lambda}\left(1-e^{(-\lambda t)}\right)
$$

Where $C_{0}$ is radon concentration when time $t=0\left(\mathrm{~Bq} \cdot \mathrm{m}^{-3}\right)$ and $t$ is the exposure time $(\mathrm{h})$.

Applying the maximum mathematical condition, the maximum concentration of radon in air $\left(C_{\max }\right)$ corresponds to the Eq. (4):

$$
C_{\max }=\frac{\phi}{\lambda}
$$

This model will be applied for air radon concentration. From the adjustment of the equation of the CCM, the value of the maximum radon concentration that will be reached in the system when there is not water inside it, the source emission rate as well as the decay constant will be obtained. 


\subsubsection{Radon Source characterization}

In order to characterize the radon source, the pitchblende stone is introduced inside the tank (see Figure 1 (B)) and the accumulation of radon in air is analyzed for 48 hours by the RadonScout detector, which was placed over the metallic bracket. During the exposure period, the tank was hermetically sealed in order to keep the different variables constant (pressure, temperature and humidity). The results on this test are adjusted according to the Close Compartment Model described previously in point 2.2.2.

\subsubsection{Study of radon in water influence on radon in air}

Once the source characterization is finished, the study of radon concentration evolution in water and air can be carried out. For this purpose, the experimental tank ( $120 \mathrm{~L}$ capacity) was filled with $50 \mathrm{~L}$ of drinking water. The pitchblende stone was placed at the bottom of the deposit and the RadonScout Plus and Corentium Pro detectors were located over the metallic support (see Fig. 1 (C)). The immersion of the pitchblende stone inside the water allows its enrichment, increasing radon concentration of water.

While the water is enriched, radon diffuses to the air where it tends to accumulate since the tank is hermetically sealed. The radon concentrations in water and in air were measured simultaneously by the Hidex 600SL and by the RadonScout Plus and Corentium Pro detectors, respectively.

For water measurements, samples were taken by the tap of the tank in small vials. This sampling procedure avoided aeration water enabling more accurate measurements. Excessive bubbling would result in higher radon transfer into the air before being measured in water. At the same time, RadonScout detector was measuring continuously (for interval integration periods of 1 hour) the amount of radon in air which is accumulated inside the container.

In this section, the experimental variation of radon concentration in the tank, both in water and air phases, will be studied by a mass balance. Radon concentration, which depends by the exposure period in the experimental device, should be the sum of air and water radon concentration considering each volume according to the Eq. (5):

$$
V_{\text {total }} C_{R n}(t)=V_{\text {water }} C_{\text {water }, t}+V_{\text {air }} C_{\text {air }, t}
$$

Where $V_{\text {total }}$ is the tank volume $\left(\mathrm{m}^{3}\right), C_{R n}(t)$ is radon concentration in the tank in a certain time $(\mathrm{t})$ according to the theoretical model $\left(\mathrm{Bq} \cdot \mathrm{m}^{-3}\right)$ predicted by the CCM model, $V_{\text {water }}$ the water volume $\left(\mathrm{m}^{3}\right), V_{\text {air }}$ is the air volume $\left(\mathrm{m}^{3}\right)$, $C_{w a t e r, t}$ and $C_{a i r, t}$ are the radon concentrations in water and in air in the tank at the same instant $t$, respectively.

With the same purpose of analyzing radon distribution between two phases, the Ostwald coefficient for an equilibrium situation (Schubert et al, 2012) is considered according to Eq 6:

$$
K_{\text {Ostwald }}=\frac{C_{\text {Water }, t}}{C_{\text {air }, t}}
$$
2018):

This parameter depends on the temperature of the system $\left(\mathrm{T}\right.$ in $\left.{ }^{\circ} \mathrm{C}\right)$, according to the following expression (González,

$$
K_{\text {Oswtald }}=0.425 e^{(-0.05 T)}+0.1
$$

\subsection{Study of the influence of radon levels in water on the air in a real installation}

In order to perform radon measurements in water and air in a real situation, it has been analyzed radon concentrations in a Waste Water Pre-Treatment Plant (WWPTP), an industry that works with high amounts of water. It is located in the northern part of Comunitat Valenciana, at the Mediterranean Coast, in Spain. Its dimension is about $800 \mathrm{~m}^{3}$ with an input flow of water of $12000 \mathrm{~m}^{3} / \mathrm{day}$. This plant has been selected, as the feed water is known to have significant levels of radon, which is transferred and accumulated into the air inside the plant.

Radon measurements in water and air inside the WWPTP have been carried out using the E-PERM H20 detection system. Likewise, air radon concentration has been measured with electrets screwed to a chamber.

\section{Results}

\subsection{Study of radon source characterization}

For the purpose to characterize the pitchblende stone and adjusting the obtained results to the theory equation (3), the concentration of radon in air inside the tank in the absence of water has been analyzed. The average temperature in the laboratory was $22{ }^{\circ} \mathrm{C}$; the relative humidity $88 \%$, and the pressure $1018 \mathrm{mbar}$, approximately. An ANOVA test has analyzed the possible dependence of the concentration of radon in air with these three variables. The results show there is no statistically significant difference between radon concentration and atmospheric variables. From data, air radon concentration is accumulating inside the hermetic tank ranging between 0 and $9.28 \times 10^{5} \mathrm{~Bq} \cdot \mathrm{m}-3$. The adjustment of experimental results to the exponential equation of the CCM model (1) is also shown in Fig. 2. 


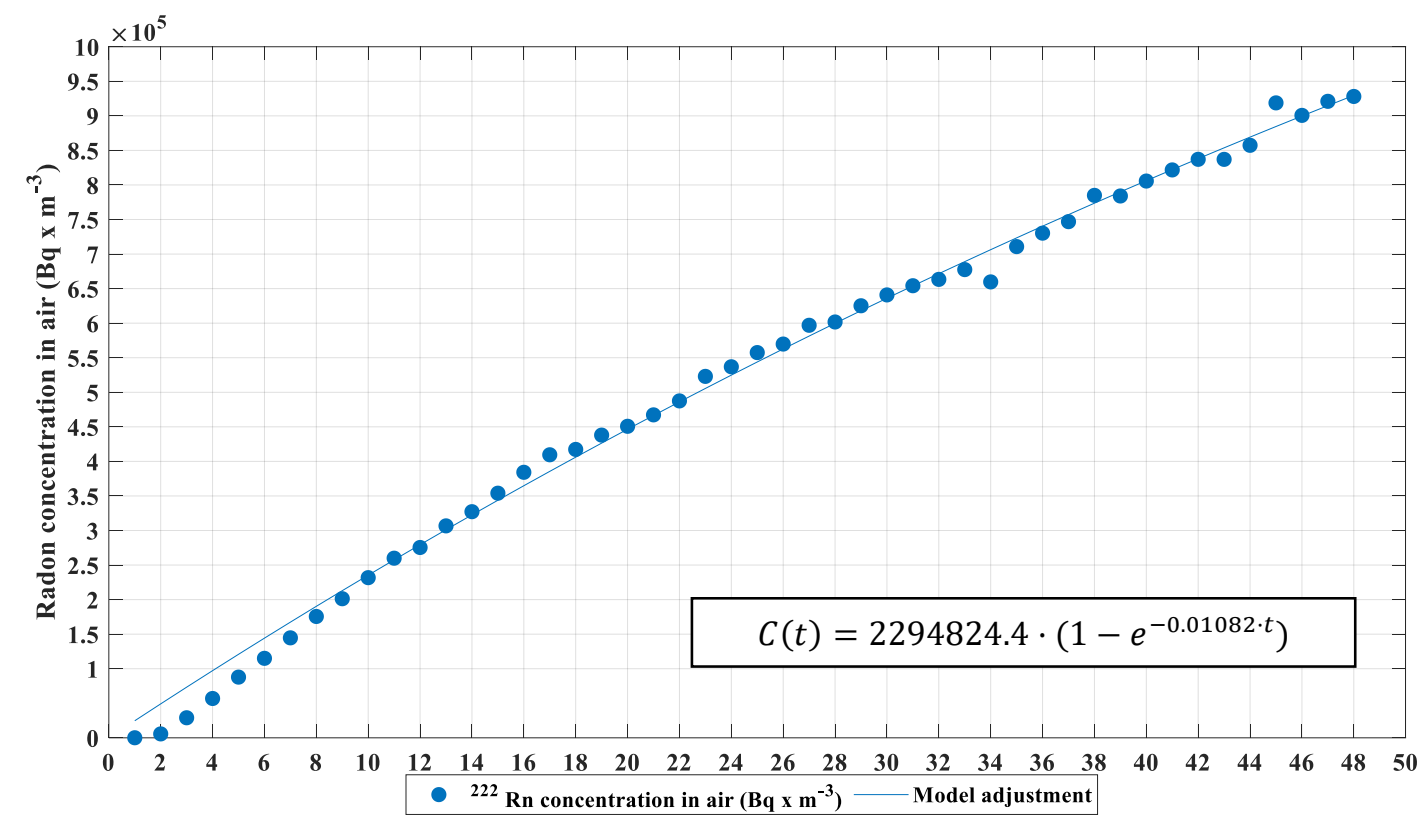

Fig. 2. Air radon concentration for source characterization

The results are adjusted to the exponential equation (3) with an R-square set at 0.99. In this way, it is possible to obtain the parameters of the CCM theoretical model which are shown in Table 1.

Table 1. Obtained parameters by the adjustment CCM

\begin{tabular}{ll}
$C_{0}\left(\mathrm{~Bq} \cdot \mathrm{m}^{-3}\right)$ & 0 \\
\hline$\Phi\left(\mathrm{Bq} \cdot \mathrm{m}^{-3} \cdot \mathrm{h}^{-1}\right)$ & $24820 \pm 910$ \\
\hline$\lambda\left(\mathrm{h}^{-1}\right)$ & $0.01082 \pm 0.00215$ \\
\hline$C_{\max }\left(\mathrm{kBq} \cdot \mathrm{m}^{-3}\right)$ & 2293.90
\end{tabular}

These results allow knowing the values of radon maximum concentration in air as well as the theoretical one during a certain period of time, with no water inside the tank. The pitchblende emission radon rate is $24820 \pm 910 \mathrm{~Bq} \cdot \mathrm{m}^{-3} \cdot \mathrm{h}^{-1}$.

\subsection{Study of the influence of radon in water on radon in air at a laboratory scale}

Once the radon source characterization is finished, the experimental tests using water in the tank were performed, and values of radon in water and in air were measured. Results in water, calculated as the average of five samples measuring during 14 days by the Hidex 600 SL detector, are shown in Fig.3. As it can be seen, in just two days, the concentration increases rapidly and then begin to stabilize, ranging from $690 \pm 18$ up to $1426 \pm 26 \mathrm{~Bq} \cdot \mathrm{L}^{-1}$. As noted, radon water enrichment has been successful.

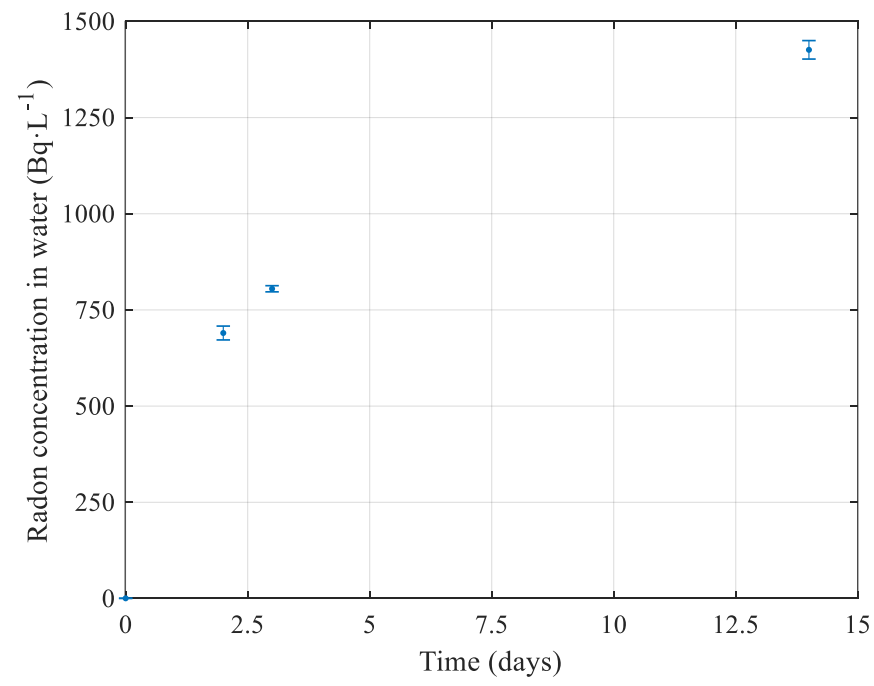

Fig. 3. Radon concentration in water in the experimental device 
Likewise, it has been analyzed, by RadonScout and CorentiumPro detectors, air radon concentration inside the tank while there was enriched water in it. The results are shown in the Fig 4.

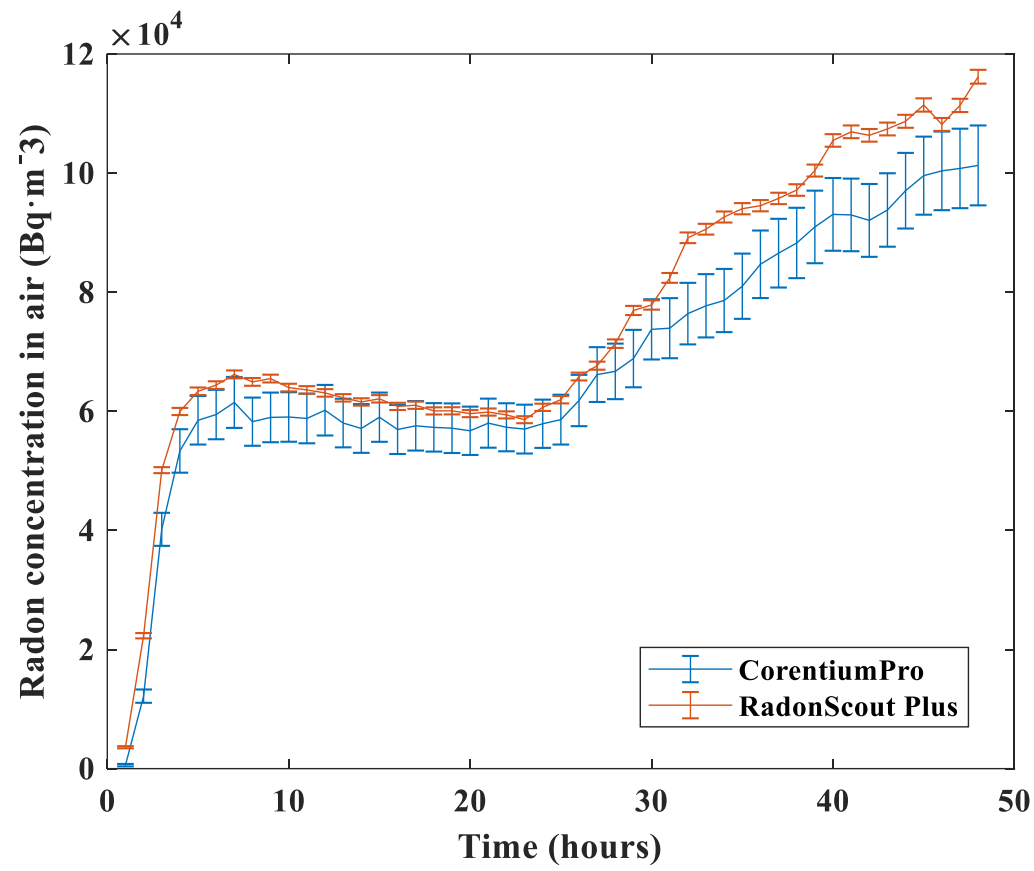

Fig. 4. Air radon concentration when the tank is filled with water

It is observed that there is an increase of air radon concentration during the sampling period. Initially, during 5 hours, it increases until reaching approximately $6 \times 10^{3} \mathrm{~Bq} \cdot \mathrm{m}^{-3}$. Subsequently, for a time of about 20 hours, this concentration of radon remains constant and after 20 hours, it increases to a value of $11.62 \times 10^{4} \pm 11.61 \times 10^{2} \mathrm{~Bq} \cdot \mathrm{m}^{-3}$ (measured by RadonScout) and $10.13 \times 10^{4} \pm 67.0710^{2} \mathrm{~Bq} \cdot \mathrm{m}^{-3}$ (measured by Corentium Pro).

The trend of the radon results variation in air shows certain stagnation for a short period of time, mainly due to the slow diffusion process from water to air when water retains the gas from transferring to air.

As it is shown, the same trend has been obtained by the two different detectors, which confirm the repeatability of results and the behavior of radon diffusion in water when there is not stirring.

In order to verify the mass balance of radon in the experimental tank, equation (5) has been applied at $t=48$ hours, resulting in the values shown in Table 2.

Table 2. Radon concentration in water and air in experimental device

\begin{tabular}{lc}
$V_{\text {total }} C_{R n}(t)(\mathrm{Bq})$ & 108000 \\
\hline$V_{\text {water }} C_{\text {water }, t}(\mathrm{~Bq})$ & 34500 \\
\hline$V_{\text {air }} C_{\text {air }, t}(\mathrm{~Bq})$ & 8120 \\
\hline$V_{\text {water }} C_{\text {water }, t}+V_{\text {air }} C_{\text {air }, t}(\mathrm{~Bq})$ & 42620
\end{tabular}

As it can be seen, the amount of radon $(\mathrm{Bq})$ obtained at 48 hours by the designed system $\left(V_{w a t e r} C_{w a t e r, t}+V_{\text {air }} C_{\text {air }, t}\right)$ is much lower than the theoretical calculated value $\left(V_{\text {total }} C_{R n}(t)\right)$. This can be explained by the values of diffusion coefficient of radon in air (gas) and in water (liquid), since the value of the diffusion coefficient of a solute, in this case radon, in a gas ranges around $10^{-4} \mathrm{~m}^{2 \cdot} \mathrm{s}^{-1}$, while the diffusion coefficient of the same solute in a liquid ranges from $10^{-9}$ to $10^{-10} \mathrm{~m}^{2} \cdot \mathrm{s}^{-1}$ (Treybal, 1980). Therefore, the diffusion of a solute in a liquid is much smaller than in a gas because the particles are closer to each other compared to those of the gas and the molecules of the solute. So, radon, which diffuses, will collide with those of the liquid (water) molecules more frequently and will diffuse more slowly than in air. This justifies that the radon concentration in the tank in the absence of water is much higher than when the liquid is added. As future research and according to the obtained results, a mathematical model will be developed, such as that of the CCM, but in this case apply for the study of the evolution of radon concentration in water. This requires a larger number of samples both in shorter periods (by hours) and longer periods (more exposure days).

Following the analysis of the radon distribution between the two phases inside the tank, its solubility has been analyzed from the Ostwald coefficient. First of all, the value of this coefficient has been calculated considering $20^{\circ} \mathrm{C}$ of temperature, which is the average of the temperatures measured inside the experimental device for all tests. Using equation (6) a value of 0.256 for $K_{\text {Ostwald }}$ has been obtained, which is in accordance with literature (Pritchard et Gessell, 1977; Schubert et al, 2012). 
Considering the Ostwald coefficient calculated by Eq.6, the air radon concentration that should be obtained by the experimental test, if the equilibrium in two phases was achieved, is:

$$
0.256=\frac{6.9 \times 10^{5}}{C_{\text {air }, t}} x\left(1000 \mathrm{~L} \cdot \mathrm{m}^{-3}\right) \rightarrow C_{\text {air }, t}=26.9 \times 10^{5} \mathrm{~Bq} \cdot \mathrm{m}^{-3}
$$

It has been observed that this theoretical value for air radon concentration is much greater than the experimental value, of $1.162 \times 10^{5} \mathrm{~Bq} \cdot \mathrm{m}^{-3}$ measured at laboratory scale. Therefore, by the testing results it is shown that the equilibrium between air and water radon concentration has not reached.

\subsection{Analysis of radon concentration in water and air inside the WWPTP}

The average measured values of the air and water radon concentrations for consecutive years are shown in Table 3 .

Table 3. Air and water radon concentration in the WWPTP

\begin{tabular}{lcccc}
\hline \multicolumn{1}{c}{ Exposure period } & $\begin{array}{c}\text { Water radon concentration } \\
\left(\mathrm{Bq} \cdot \mathrm{L}^{-1}\right) \text { by RAD7 }\end{array}$ & $\begin{array}{c}\text { Water } \\
\text { temperature } \\
\left({ }^{\circ} \mathrm{C}\right)\end{array}$ & $\begin{array}{c}\text { Air radon concentration } \\
\left(\mathrm{Bq} \cdot \mathrm{m}^{-3}\right) \text { by E-PERM }\end{array}$ & $\begin{array}{c}\text { Atmospheric } \\
\text { conditions }\end{array}$ \\
\hline \hline & $41.50 \pm 2.80$ & $15 \sim 23$ & $677 \pm 34$ & $\begin{array}{r}\mathrm{T}=20 \sim 22^{\circ} \mathrm{C} \\
\mathrm{HR}: 55 \sim 77 \% \\
\mathrm{P}=1018 \mathrm{mbar}\end{array}$ \\
\hline $\begin{array}{l}\text { Test 1: March to June } \\
\begin{array}{l}\text { April } \\
\text { Test February to }\end{array}\end{array}$ & $34 \pm 2.20$ & $13 \sim 16$ & $634.30 \pm 43$ & $\mathrm{~T}=13 \sim 14^{\circ} \mathrm{C}$ \\
$\mathrm{HR}: 55 \sim 77 \%$
\end{tabular}

In this table, the water and air radon concentrations are shown for each exposure period. For technical reasons, the measurements made in water were carried out by the RAD7 and the air measurements were taken by the E-PERM System.

Focusing on the results shown in Table 3, radon in water values range between $34 \pm 2.2$ and $41.5 \pm 2.8 \mathrm{~Bq} \cdot \mathrm{L}^{-1}$ without exceeding the legislative limits for water consumption, set at 500-1000 Bq $\cdot \mathrm{L}^{-1}$ (Real Decreto 314/2016). However, air radon concentration in air, varying from $634.30 \pm 43$ until $677 \pm 34 \mathrm{~Bq} \cdot \mathrm{m}^{-3}$, exceeds the exposure limit in each measure, according to limit set at $300 \mathrm{~Bq} \cdot \mathrm{m}^{-3}$ by the Directive 2013/59/EURATOM and $600 \mathrm{~Bq} \cdot \mathrm{m}^{-3}$ at Real Decreto $783 / 2001$, since Spanish limits are not updated according to European legislation. It is important to highlight the fact that levels of water concentrations below the legal limit can result in values of air radon concentration higher than limits, as it can be seen in the results of this study. This indicates that some measures to reduce air radon concentration inside the WWPTP should be implemented to preserve workers' health.

\subsection{Comparison between results at laboratory scale and in the real installation}

The aim of this section is to compare results of measured concentrations in water and air both at laboratory scale and in the real installation. For this purpose, a proportionality coefficient between the two variables (adequately considering the units) has been calculated according to the following equation:

$$
\text { Proportionality coefficient }=\frac{C_{R n, \text { water }}\left(B q \cdot L^{-1}\right)}{C_{R n, \text { air }}\left(B q \cdot m^{-3}\right)} \times 1000\left(L \cdot \mathrm{m}^{-3}\right)
$$

Measured values as well as the proportionality coefficient that relates both measurements in water and in air is shown in Table 4:

Table 4. Comparison of laboratory scale and real installation

\begin{tabular}{cccc} 
Measurement point & $\begin{array}{c}\text { Water radon concentration } \\
\left(\mathrm{Bq} \cdot \mathrm{L}^{-1}\right)\end{array}$ & $\begin{array}{c}\text { Air radon concentration } \\
\left(\mathrm{Bq} \cdot \mathrm{m}^{-3}\right)\end{array}$ & \begin{tabular}{c} 
Proportionality coefficient \\
\hline Experimental device
\end{tabular} \\
\hline WWPTP-Test 1 & $41.50 \pm 0.18$ & $116200 \pm 1161$ & 5.94 \\
\hline WWPTP- Test 2 & $34 \pm 2.20$ & $677 \pm 34$ & 61.29 \\
\hline
\end{tabular}

As it is seen in Table 4, air and water radon concentrations are much higher at the experimental device. Water radon concentration measured by the experimental device is more than 16 times higher than the measured at the WWWPTP, while air radon concentration is more than 171 times higher. However, the proportionality coefficient between the concentration of radon in water and in air for the experimental equipment is around 10 times lower than that obtained in the case of the real installation, in spite of showing a radon concentration in water significantly higher. This result can be explained by the fact there is a greater transfer of radon from water to air due to the water turbulence generated by stirring during the treatment process at the WWPTP, whereas the analyzed water at the experimental device is in a steady state.

Although the transfer is expected to be higher for a real situation under turbulence in water, in terms of radon concentration, the values are much lower than the ones in the experimental device because the volume in which radon gas diffuses is much greater. 
According to these results, laboratory scale tests under turbulence conditions should be performed to determine the radon flux from water to air in dynamic conditions more similar to those of the real installation.

\section{Conclusions}

The main objective of this research, studying radon in water influence on radon levels in air at laboratory scale and in a real installation, has been achieved satisfactorily. In order to develop measurements at a laboratory scale, it has been designed an experimental device that allows to enrich the water with radon, as well as to study the influence of radon concentration in water on radon levels in air. Additionally, measurements have been made in monitored and controlled conditions of temperature, humidity and pressure. This makes it possible to demonstrate the stability of the system and reproducibility of the obtained results.

First of all, through this device, a pitchblende stone as a radon source has been characterized. Its emission rate $(\phi=$ $\left.24820 \pm 910\left(\mathrm{~Bq} \cdot \mathrm{m}^{-3} \cdot \mathrm{h}\right)\right)$ as well as the maximum concentration in air that could reach in the designed system $\left(\mathrm{C}_{\max }=\right.$ $2293.90 \mathrm{kBq} \cdot \mathrm{m}^{-3}$ ) has been obtained. Results have been adjusted by the Closed Compartment Model (CCM) with a RSquare of 0.99. Likewise, with the experimental device, it has been possible to enrich a certain amount of water successfully, reaching radon concentration of $1426 \pm 26 \mathrm{~Bq} \cdot \mathrm{L}^{-1}$ in 14 days, measured by Hidex 600SL. Therefore, the experimental system has been very useful for obtaining water with radon in the laboratory. In addition, in future research a mathematical model will be developed that allows predicting the concentration of radon in water as it has been done for air.

On the other hand, the concentration of radon in air inside the deposit was analyzed by the RadonScout Plus and Corentium Pro detectors when the water was already enriched. Radon concentration initially increases, then stabilizes for less than 20 hours and then increase to a value of $1.162 \cdot 10^{5} \mathrm{~Bq} \cdot \mathrm{m}^{-3}$. The trend of the curve of radon concentration values in air shows certain stagnation for a short period of time, mainly due to the diffusion radon process, which is lower in water than in air. After this plateau, the diffusion of water into the air through the interface increases again. Moreover, experimental and theoretical radon concentration inside the tank have been calculated and a clear difference between them is observed that can be due to the difference in diffusion rate through water comparing to the one in air. It is also observed that the trend of air radon concentration is quite similar with both detectors, which confirms the reproducibility of the results at the experimental device.

In addition, radon concentration in water and in air in a Waste Water Pre-Treatment Plant has been analyzed. Values in water are below the legislative limit (500-1000 Bq. $\mathrm{L}^{-1}$, Real Decreto 314/2016) for human consumption. However, for air radon concentration the legal limits $\left(300 \mathrm{~Bq} \cdot \mathrm{m}^{-3}\right.$, Directive 2013/59/EURATOM) are exceed, probably due to the effect of the water turbulence during its treatment process, increasing radon transfer to air.

It is also analyzed the proportionality coefficient between the concentration of radon in water and in air at a laboratory scale and in a real installation (WWPTP). The difference between coefficients, which is 10 times lower for the experimental device, confirms the importance of the aeration and bubbling process at the WWPTP which helps radon transfer increasing its concentration in air.

From all the results obtained both through experimental equipment and field measurements, a clear influence of radon concentration in water on the air is observed for a closed location. Future studies are required to define the transfer of radon from water to air, both at laboratory and real scale, under steady and turbulence conditions, to be able to predict radon concentrations in both situations.

\section{Acknowledgments}

This work has been funded by two projects: BIORAD and DESARROLLO DE METODOLOGÍAS DE PREVENCIÓN Y DE MODELOS DE DOSIMETRÍA INTERNA PARA LAS RADIACIONES IONIZANTES RELACIONADAS CON MATERIALES NORM (MEMO RADIÓN) of the ISIRYM University Institute in the framework of the Operational Programme 2014-2020 Comunitat Valenciana of the European Regional Development Fund, with reference IDIFEDER/2018/038.

\section{References}

Baudron, P., Cockenpot, S., Lopez-Castejon, F., Radakovitch, O., Gilabert, J., Mayer, A., ... \& Claude, C. (2015). Combining radon, short-lived radium isotopes and hydrodynamic modeling to assess submarine groundwater discharge from an anthropized semiarid watershed to a Mediterranean lagoon (Mar Menor, SE Spain). Journal of Hydrology, 525, $55-71$.

Battino, R. (1984). The Ostwald coefficient of gas solubility. Fluid phase equilibria, 15(3), 231-240.

Cantaloub M.G., Higginbotham J.F., Semprini, L., The determination of Rn partition coefficients for several liquid scintillation cocktails. Oregon State University, Corvallys.

Cartografía del Potencial de radón en España M-5767 (2017). Consejo de Seguridad Nuclear, CSN.

Cherta Val, A., Baixeras Divar, C., \& García i Orellana, J. (2008). Nivells de radó en exterior i recintes tancats a la marjal càrstica de Peníscola.

Gonzalez, S. C. (2018). Estudio del comportamiento del 222Rn en los procesos de recarga-descarga en acuíferos: simulación en laboratorio y aplicación a un caso real (Doctoral dissertation, Universidad de Cantabria). 
Kotrappa, P. (1996). E-PERM System Manual Part II, 11: Modified E-PERM for Passive Measurements of Thoron in Air. Rad Elec Inc., Frederick, MD.

Kowalczk, A. J., \& Froelich, P. N. (2010). Cave air ventilation and CO2 outgassing by radon-222 modeling: how fast do caves breathe. Earth and Planetary Science Letters, 289(1-2), 209-219.

Soto, J., Fernandez, P. L., Quindos, L. S., \& Gomez-Arozamena, J. (1995). Radioactivity in Spanish spas. Science of the total environment, 162(2-3), 187-192.

Matos, L. E. (1997). Riesgo de cáncer en exposiciones ocupacionales. Rev Gerencia Ambiental, 5(33), 36-42.

Manual, RAD7. Radon Detector User Manual (2000). Durridge co.

Moreno, V., Bach, J., Baixeras, C., \& Font, L. (2014). Radon levels in groundwaters and natural radioactivity in soils of the volcanic region of La Garrotxa, Spain. Journal of environmental radioactivity, 128, 1-8.

Moreno, V., Cherta, A., Rodellas, V., García-Solsona, E., García-Orellana, J., \& Baixeras, C. (2009). Resultados preliminaries de los niveles de Radón en la marjal de Peñíscola. Radioprotección num, 60, 17.

Nussbaum, E., \& Harsh, J. B. (1958). Radon solubility in fatty acids and triglycerides. The Journal of Physical Chemistry, 62(1), 81-84.

Noverques Medina, A. (2018). Desarrollo de la norma UNE-EN ISO/IEC 17025 para la competencia del Laboratorio de Radiactividad Ambiental de la UPV en la acreditación de la medición de radón en aire. Universitat Politècnica de València.

Noverques Medina, Aina (2017). Trabajo Final de Máster. Desarrollo de metodologías para la realización de mediciones de exhalación de Radón 222. Universitat Politècnica de València.

Pritchard, H.M., Gessell, T.F. Rapid determination of radon-222 concentrations in water with a comercial liquid scintillation counter, Health Physics. 33(5):577,1977.

Real Decreto 314/2016, de 29 de julio, por el que se establecen los criterios sanitarios de la calidad del agua de consumo humano. Boletín Oficial del Estado. Madrid, 30 de julio de 2016, núm. 183, pp 53106

Rodellas i Vila, V. (2008). Distribució de radionúclids naturals en una marjal càrstica del Mediterrani occidental: la marjal de Peníscola.

Ródenas, C., Gómez, J., Soto, J., \& Maraver, F. (2008). Natural radioactivity of spring water used as spas in Spain. Journal of Radioanalytical and Nuclear Chemistry, 277(3), 625-630.

Sainz, C., Rábago, D., Fuente, I., Celaya, S., \& Quindós, L. S. (2016). Description of the behavior of an aquifer by using continuous radon monitoring in a thermal spa. Science of The Total Environment, 543, 460-466.

Schubert, M., Paschke, A., Lieberman, E., \& Burnett, W. C. (2012). Air-water partitioning of ${ }^{222}$ Rn and its dependence on water temperature and salinity. Environmental science \& technology, 46(7), 3905-3911.

Treybal, R. E. (1980). Mass transfer operations. New York, 466.

User Manual CorentiumPro (2008). Airthings AS.

User Manual E-PERM System. Radon in water (2008). Rad Elec Inc.

User Manual RAD7 (2007), Durridge Company Inc.

User Manual Radon Scout Plus, (2017) Sarad Company.

WHO. Handbook on Indoor Radon. A Public Health Perspective (2009)

Zeeb, h., \& shannoun, f. (2015). Manual de la OMS sobre el radón en interiores: una perspectiva de salud pública. 